\title{
Plasma concentrations of caspofungin in a critically ill patient with morbid obesity
}

\author{
Rafael Ferriols-Lisart ${ }^{1 *}$ (D), Gerardo Aguilar², Alejandro Pérez-Pitarch', Jaume Puig², Carlos Ezquer-Garín ${ }^{3}$ \\ and Manuel Alós ${ }^{1}$
}

The aim of the study was to describe the pharmacokinetic behaviour of caspofungin in a critically ill patient with morbid obesity who received doses of caspofungin higher than labelled doses.

A 57 -year-old morbidly obese man $\left(\mathrm{BMI}=50 \mathrm{~kg} / \mathrm{m}^{2}\right)$ was admitted to our ICU after surgical treatment of anastomotic leak in the postoperative period of elective laparoscopic bariatric surgery. The patient was in septic shock, with Candida multicolonization and other risk factors of invasive candidiasis. We decided to start antimicrobial treatment, including meropenem, linezolid and caspofungin. With the intention of maximizing the potential effectiveness of antifungal treatment, caspofungin at a dose of $100 \mathrm{mg} /$ day was chosen. The caspofungin dose was calculated using a population pharmacokinetic model [1]. Target AUC/MIC was set at 860 and therefore AUC values above $107 \mathrm{mg}$ "h/L were necessary assuming $\mathrm{MIC}=0.125 \mathrm{mg} / \mathrm{L}$ [2]. After administration of the first dose, Cpeak was $4.51 \mathrm{mg} / \mathrm{L}$, Ctrough was $0.94 \mathrm{mg} / \mathrm{L}$ and AUC was $115.9 \mathrm{mg}$ *h/L. Three days later, Cpeak was $5.97 \mathrm{mg} / \mathrm{L}$, Ctrough was $1.76 \mathrm{mg} / \mathrm{L}$, AUC was $140.4 \mathrm{mg}^{*} \mathrm{~h} / \mathrm{L}$ and AUC/MIC was 1123 . The manufacturer recommends caspofungin dose reduction when AUC values are above $210 \mathrm{mg}$ *h/L and, accordingly, drug exposure was considered safe. The patient became apyretic 10 days after caspofungin treatment initiation; this lasted for 14 days without any adverse effects related to this drug.

There are conflicting data on dosing recommendations in obese patients [3]. Payne and Hall [4] found that lower caspofungin AUC was achieved in obese people than in thinner ones, suggesting that dose optimization in heavier patients might improve

\footnotetext{
* Correspondence: ferriols_raf@gva.es

${ }^{1}$ Department of Pharmacy, University Clinical Hospital of Valencia, Avda.

Blasco Ibañez 17, Valencia, Spain

Full list of author information is available at the end of the article
}

clinical success rates. If the labelled dose of $70 \mathrm{mg} /$ day had been used in our patient, AUC/MIC would have been 786, below the target AUC/MIC value. Figure 1 shows caspofungin concentrations over time for doses of 100 and $70 \mathrm{mg} /$ day. A dose of $150 \mathrm{mg} /$ day has been recommended in obese patients until simulation studies are completed to provide a bedside dosing formula for caspofungin [4]. There are reports of deterioration of hemodynamic parameters during loading doses in critically ill patients [5]. The monitoring of hemodynamic parameters in these patients is highly recommended. The dose of caspofungin should be adjusted according to both serum caspofungin concentrations and clinical symptoms. However, determination of caspofungin concentrations is performed at only a few laboratories, which makes routine monitoring difficult. This case suggests that caspofungin doses higher than those recommended by the manufacturer may be needed to reach pharmacokinetic/pharmacodynamic targets in ICU morbidly obese patients.

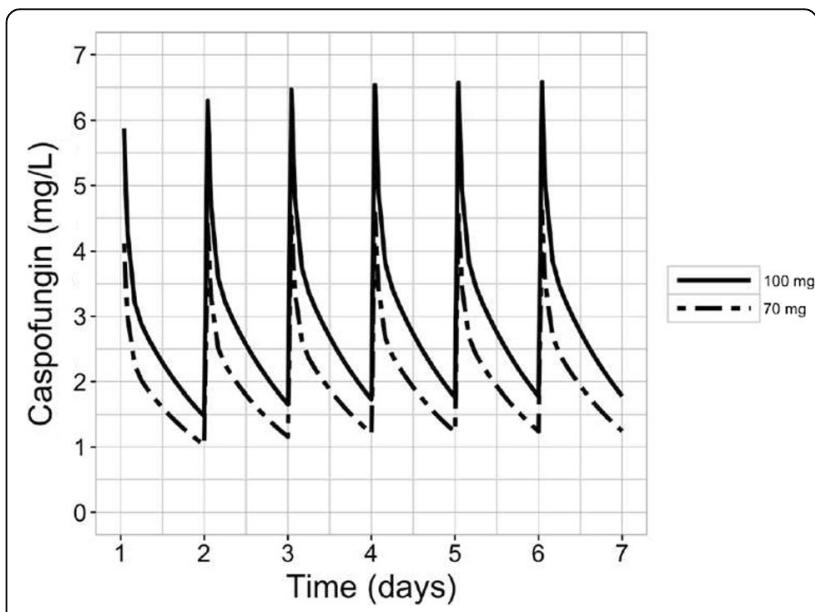

Fig. 1 Concentration-time curve for a schedule treatment of $100 \mathrm{mg} /$ day caspofungin versus $70 \mathrm{mg} /$ day in a morbidly obese patient 


\section{Abbreviations}

AUC: Area under the concentration-time curve; BMl: Body mass index; Cpeak: Maximum concentration; Ctrough: Trough concentration; ICU: Intensive Care Unit; MIC: Minimum inhibitory concentration required to inhibit the growth of $90 \%$ of a microorganism

\section{Acknowledgements}

Not applicable.

\section{Funding}

This research did not receive any specific grant from funding agencies in the public, commercial, or not-for-profit sectors.

\section{Availability of data and materials}

All relevant data are within the paper. The datasets used and/or analysed during the current study are available from the corresponding author on reasonable request.

\section{Authors' contributions}

FLR conceived the study, participated in designing and coordinating the study and drafted the manuscript. AG participated in study conception, acquisition and interpretation of data and helped to draft the manuscript. PPA participated in study design, carried out the pharmacokinetic analysis and helped to draft the manuscript. PJ participated in study conception, acquisition of data and helped to draft the manuscript. EGC participated in analyzing serum data and helped to draft the manuscript. AM participated in study conception, design of the study and helped to draft the manuscript. All authors read and approved the final manuscript.

\section{Ethics approval and consent to participate}

The study protocol (CASP-MO-2017) was approved by the local ethics committee (Instituto de Investigación Sanitaria, INCLIVA) and written informed consent obtained from the patient's legal representative prior to study inclusion.

\section{Consent for publication}

Written informed consent was obtained from the patient's legal representative for publication of their individual details. The consent form is held by the authors' institution and is available for review by the Editor-in-Chief.

\section{Competing interests}

GA received funds for speaking at meetings organized on behalf of Astellas, Gilead, Merck Sharp and Dohme (MSD) and Pfizer, as well as unrestricted research grants from Astellas, MSD and Pfizer. All other authors declare no conflicts of interest.

\section{Publisher's Note}

Springer Nature remains neutral with regard to jurisdictional claims in published maps and institutional affiliations.

\section{Author details}

'Department of Pharmacy, University Clinical Hospital of Valencia, Avda. Blasco Ibañez 17, Valencia, Spain. ${ }^{2}$ Surgical Intensive Care Unit, Department of Anesthesiology and Intensive Care, Hospital Clínico Universitario, Valencia, Spain. ${ }^{3}$ Health Research Institute, INCLIVA, Avenida Blasco Ibáñez 17, 46010 Valencia, Spain.

\section{Published online: 02 August 2017}

\section{References}

1. Pérez-Pitarch A, Ferriols-Lisart R, Aguilar G, et al. Dosing of caspofungin based on a pharmacokinetic/pharmacodynamic index for the treatment of invasive fungal infections in critically ill patients on continuous venovenous haemodiafiltration. Int J Antimicrob Agents. 2017. doi:10.1016/j.ijantimicag. 2017.05.013.

2. Aguilar G, Ferriols R, Lozano A, et al. Optimal doses of caspofungin during continuous venovenous hemodiafiltration in critically ill patients. Crit Care. 2017:21:17.

3. Song JC, Stevens DA. Caspofungin: pharmacodynamics, pharmacokinetics, clinical uses and treatment outcomes. Crit Rev Microbiol. 2016;42(5):813-46. doi:10.3109/1040841X.2015.1068271.
4. Payne K, Hall R. Dosing of antifungal agents in obese people. Expert Rev Anti Infect Ther. 2016;14(2):257-61. doi:10.1586/14787210.2016.1128822.

5. Lahmer T, Schnappauf C, Messer M, et al. Influence of echinocandin administration on hemodynamic parameters in medical intensive care unit patients: a single center prospective study. Infection. 2015;43(6):723-7. doi:10.1007/s15010-015-0828-0. 